\title{
Dimensão técnico-operativa do trabalho do Assistente Social nas penas e medidas alternativas: aproximações a partir de uma pesquisa documental e bibliográfica
}

\author{
Technical and operative dimension of the Social Assistant job in alternative penalties and \\ measures: approaches from a documental and bibliographic research
}

Maíz Ramos Junqueira*

\begin{abstract}
Resumo
Neste artigo são apresentadas algumas reflexões sobre a dimensão técnico-operativa do trabalho do assistente social na execução das penas e medidas alternativas no Brasil. As informações expostas foram obtidas mediante a realização de pesquisa documental e bibliográfica sobre o tema. Afirma-se a relevância da discussão sobre a dimensão técnico-operativa do Serviço Social, entendendo-a de maneira articulada às demais dimensões da profissão (teórico-metodológica e ético-política). Parte-se da compreensão do caráter contraditório das penas, medidas, alternativas e de suas repercussões para os assistentes sociais que atuam nesse campo, que possui uma relação histórica com o exercício do controle social. Busca-se, a partir da elaboração deste artigo, contribuir para a reflexão dos profissionais sobre a violência que acompanha as respostas do Estado na esfera penal e a necessidade de movimentos que contribuam para desvelar e reconhecer essa dimensão.
\end{abstract}

Palavras-chave: Dimensão técnico-operativa. Serviço social. Penas e medidas alternativas. Alternativas penais. Controle social.

\begin{abstract}
This article introduces a few reflections about the technical and operative dimension of the social assistant job in the execution of alternative penalties and measures in Brazil. The information conveyed herein was obtained by means of documental and bibliographic research on the issue. The relevance of the discussion about the Social Service technical and operative dimension is highlighted while it is understood as articulated with other dimensions of the occupation (theoretical and methodological as well as ethical and political). The starting point is understanding the contradictory nature of the alternative penalties and measures and their repercussions for the social assistants who perform in this field that has an historical relation with the exercise of social control. The elaboration of this article aims to contribute for the professionals 'reflection about the violence present within the answers of the State in the penal sphere and the need of movements that might contribute to unveil and to recognize such dimension.
\end{abstract}

Keywords: Technical and operative dimension. Social service. Alternative penalties and measures. Penal alternatives. Social control

\footnotetext{
${ }^{*}$ Assistente social do Poder Judiciário do Estado do Rio Grande do Sul. Especialista em Direito da Criança e do Adolescente pela Fundação Escola Superior do Ministério Público e Mestre em Educação pela Universidade Federal do Rio Grande do Sul (UFGRS). Doutora em Serviço Social na Pontifícia Universidade Católica do Rio Grande do Sul (PUCRS)
} 


\section{Introdução}

Este artigo trata sobre a dimensão técnico-operativa do trabalho do assistente social no processo de execução das penas e medidas alternativas no Brasil à luz dos fundamentos teórico-metodológicos e ético-políticos da profissão. Apresenta-se uma síntese de parte das informações coletadas e das conclusões de uma tese de doutorado em Serviço Social que objetivou analisar as interfaces da ideologia contemporânea do controle social com o trabalho do assistente social nas penas e medidas alternativas no Brasil.

O estudo, de cunho qualitativo, fundamentou-se no método dialético crítico e foi realizado mediante pesquisa bibliográfica e análise documental, com as seguintes fontes de informação: dissertações de mestrado, trabalhos de conclusão de curso (graduação), artigos científicos em periódicos, anais de eventos do Serviço Social (Encontro Nacional de Pesquisadores em Serviço Social e Congresso Brasileiro de Assistentes Sociais) e documentos produzidos por órgãos normatizadores das penas e medidas alternativas, no período compreendido entre os anos 2000 e 2016. Os procedimentos de análise dos dados foram realizados com base na Análise Textual Discursiva (MORAES; GALIAZZI, 2011).

O presente artigo está estruturado em quatro itens. Inicialmente, situa-se o tema das penas e medidas alternativas no Brasil, notadamente em relação aos seus aspectos históricos, seus avanços quanto às penas privativas de liberdade e suas contradições. Em seguida, discutem-se aspectos relacionados à dimensão técnico-operativa do Serviço Social, reconhecendo sua complexidade e relação com as demais dimensões do trabalho profissional (teórico-metodológica e ético-política). No terceiro item são apresentados os resultados da pesquisa documental e bibliográfica, refletindo-se sobre a dimensão técnico-operativa da profissão, especificamente na execução das penas e medidas no Brasil. Por fim, são delineadas as considerações finais, salientando-se a necessidade de sistematização do trabalho cotidiano e o fortalecimento da dimensão investigativa do Serviço Social.

Ressalta-se que o presente texto não ambiciona, evidentemente, esgotar o assunto, mas lançar algumas luzes sobre a dimensão técnico-operativa da profissão na execução das penas e medidas alternativas. Nessa perspectiva, pretende-se contribuir para o adensamento da produção teórica do Serviço Social nesse campo, notadamente diante do fato de se tratar de uma área ainda pouco explorada na produção bibliográfica dos assistentes sociais.

\section{Situando o Tema das Penas e Medidas Alternativas no Brasil}


As penas e medidas alternativas resultaram de um movimento internacional voltado para a construção de novas possibilidades de controle social diante do questionamento do modelo baseado na prisão. Uma das primeiras experiências ocorreu na Rússia, no ano de 1926, com a criação da prestação de serviços à comunidade. Gradativamente, outros países passaram a adotar substitutivos em relação à prisão, merecendo destaque a Inglaterra, que criou a prisão de final de semana, através da Justice Act, em 1948 (BITENCOURT, 2004).

A Declaração Universal dos Direitos Humanos, de 1948, é considerada um marco no movimento internacional em prol das penas e medidas alternativas. Embora não tenha tratado especificamente sobre o tema, a Declaração propôs, em seu artigo V, que "ninguém será submetido à tortura, nem a tratamentos ou punições cruéis, desumanas ou degradantes" (ONU, 1948).

No ano de 1955 foram editadas as Regras Mínimas para o Tratamento dos Presos pela Organização das Nações Unidas (ONU), as quais recomendam a aplicação das penas não privativas de liberdade (ONU, 1955). Em 1966, o Pacto Internacional de Direitos Civis e Políticos afirmou que "toda pessoa privada de sua liberdade deverá ser tratada com humanidade e respeito à dignidade inerente à pessoa humana" (BRASIL, 1992).

As Regras Mínimas das Nações Unidas sobre as Medidas Não Privativas de Liberdade, conhecidas como "Regras de Tóquio", de 1990, também são consideradas um importante marco na construção das propostas de alternativas à prisão em termos mundiais. Tais Regras, em síntese, propõem a promoção de medidas não privativas da liberdade e de garantias mínimas para as pessoas submetidas a medidas substitutivas da prisão.

As Regras de Tóquio influenciaram as leis penais em diversos países. No Brasil, as primeiras reformas penais que possibilitaram a construção de alternativas à prisão remontam à Lei 6.416 , de 1977, que inseriu no sistema penal brasileiro a prisão aberta, a prisão albergue e a ampliação do sursis ${ }^{1}$. A partir da década de 1980 o rol de possibilidades de penas alternativas foi ampliado mediante a previsão da liberdade vigiada, da reparação do dano e da prestação de serviços à comunidade.

No ano de 1984 foi promulgada a Lei no 7.209, que alterou o Código Penal de 1940. Foi a partir desse momento que as denominadas penas restritivas de direitos passaram a ser tratadas efetivamente como "penas alternativas" no Direito brasileiro, pois até então eram

\footnotetext{
${ }^{1}$ Sursis significa a suspensão da pena mediante o cumprimento de determinadas condições.
} 
aplicadas somente como condição no sursis. No mesmo ano foi promulgada a Lei no 7.210 , que instituiu a Lei de Execução Penal.

A partir da década de 1990 novas Leis ampliaram as possibilidades de aplicação das penas e medidas alternativas no país, merecendo destaque a Lei no 9.099, de 1995, que criou os Juizados Especiais Criminais (JECRIMs). Em 1998, a Lei no 9.714 ampliou o rol das sanções alternativas e o tempo quando impostas em substituição à prisão para até quatro anos, excluídos os delitos cometidos com violência ou grave ameaça à pessoa ${ }^{2}$. Posteriormente, outras leis foram criadas, estendendo ainda mais as possibilidades de aplicação das penas e medidas alternativas: Lei no 9.503 de 1997 (Lei de Trânsito), Lei no 9.605 de 1998 (Lei dos Crimes Ambientais), Lei no 10.826 de 2003 (Lei do Desarmamento), Lei 11.340 de 2006 (Lei Maria da Penha) e Lei no 11.343 (Lei de Drogas).

No que diz respeito aos aspectos relacionados à execução das penas e medidas alternativas, o ano 2000 representou um marco especialmente importante. Nesse período, iniciou o processo de discussão sobre uma política nacional nessa área, especialmente mediante a criação da Central Nacional de Apoio e Acompanhamento às Penas e Medidas Alternativas (CENAPA), vinculada ao Ministério da Justiça.

Inicialmente, o foco da discussão era a criação de estruturas para o monitoramento das penas e medidas alternativas, considerando-se que poucos Estados estavam equipados para tanto. Foram firmados, então, convênios com o Governo Federal, envolvendo as instituições: Poder Judiciário, Ministério Público, Defensoria Pública e Poder Executivo. A criação de Varas Especializadas em Execução de Penas e Medidas Alternativas também foi estimulada nesse período inicial.

No decorrer da década de 2000 houve significativa ampliação das estruturas de execução das penas e medidas alternativas no Brasil. Conforme Barreto (2010), no ano de 2002 o país contava com quatro varas especializadas e 26 núcleos de execução de penas e medidas alternativas. Em 2009, 20 varas especializadas haviam sido instaladas e existiam 389 centrais de penas e medidas alternativas ${ }^{3}$.

\footnotetext{
${ }^{2}$ O Código Penal prevê as seguintes penas e medidas alternativas: multa, prestação de serviços à comunidade, limitação de final de semana e interdição temporária de direitos (proibição de cargo, função, atividade pública ou mandato eletivo, proibição de exercício profissional e suspensão da habilitação para dirigir veículo). Com a Lei $\mathrm{n}$ 0 9.714/98 foram acrescentadas quatro novas possibilidades: prestação pecuniária em favor da vítima, perda de bens e valores, proibição de frequentar lugares e prestação de outra natureza.

${ }^{3}$ Barreto (2010) chama a atenção ainda para o significativo aumento na aplicação das alternativas penais nesse período. Enquanto em 2002 contabilizavam-se 102.403 penas e medidas alternativas aplicadas, no ano de 2009 o número atingiu 671.078, mais que o sêxtuplo do conhecido naquela primeira data.
} 
Diante da ampliação das estruturas de execução das penas e medidas alternativas, as discussões avançaram visando a necessidade de construção de uma política nacional nessa área. No ano de 2011 o Departamento Penitenciário Nacional (DEPEN) formou um grupo de trabalho com o objetivo de consolidar um Sistema Nacional de Alternativas Penais (SINAPE). No mesmo ano, o Ministério da Justiça criou a Estratégia Nacional de Alternativas Penais (ENAPE), com o objetivo de fomentar a política e a criação de estruturas de acompanhamento à execução das alternativas penais nos Estados e Municípios.

O conceito de alternativas penais tem sido construído mais recentemente no Brasil, conforme publicações do Ministério da Justiça ${ }^{4}$. Busca-se, dessa maneira, maior abrangência nas possibilidades de intervenção distintas da prisão, abarcando, além das penas e medidas alternativas, os institutos da conciliação, mediação, técnicas de justiça restaurativa, medidas protetivas de urgência e medidas cautelares diversas de prisão.

É importante ressaltar, contudo, que os avanços conquistados em direção à construção de uma política nacional de alternativas penais sofreram abalos e rupturas diante da conjuntura do país a partir do ano de 2016. Conforme afirma Pimenta (2017, p. 32),

[...] com o golpe de Estado conduzido por setores reacionários da sociedade brasileira em um pacto de elites, houve um resgate abrupto da crença no poder punitivo, retomando-se com força o discurso da necessidade do endurecimento das penas e dos regimes de cumprimento. Novamente, o sistema penal é alçado a papel central em um projeto de país excludente, confiando às agências punitivas a mediação das relações sociais e dos conflitos.

No cenário descrito é possível afirmar que os avanços obtidos na área das alternativas penais ficaram limitados, resultando muito mais em uma nova compreensão e em um novo vocabulário diante da escassez de investimentos nessa área. Muitos são os desafios em um país em que o "vento punitivo que sopra dos EUA se difunde junto com a verdade única do mercado." (BATISTA, 2015, p. 28). Faz-se necessário, nesse contexto, travar uma verdadeira "batalha" no sentido de construir uma política criminal orientada por um posicionamento minimalista, ou seja, que postule a restrição gradativa do uso da prisão, a redução do poder

\footnotetext{
${ }^{4}$ Nesse sentido merece especial destaque os documentos "Postulados, Princípios e Diretrizes para a Política de Alternativas Penais" (BRASIL, 2016a) e "Manual de Gestão para Alternativas Penais: penas restritivas de direitos: procedimentos, fluxos e rotinas para aplicação e acompanhamento" (BRASIL, 2016b), ambos publicados no ano de 2016 e elaborados mediante parceria entre o Ministério da Justiça (MJ), o Programa das Nações Unidas para o Desenvolvimento (PNUD/ONU) e o Conselho Nacional de Justiça (CNJ).
} 
punitivo e a defesa dos direitos humanos (ZAFFARONI, 1988, 1991; ZAFFARONI; PIERANGELI, $2015)^{5}$.

Ainda que se admitam os limites das penas e medidas alternativas no País, são inegáveis os seus avanços em relação ao encarceramento. Reconhecendo-se o potencial de violência inerente ao Sistema de Justiça, notadamente na área criminal, compreende-se que os substitutivos penais configuram uma opção mais "humanizada", pois carregam em si menores efeitos estigmatizantes em relação ao cárcere.

É importante salientar, contudo, que, mesmo quando parecem "inofensivas", as intervenções judiciais repercutem na vida dos sujeitos, muitas vezes com efeitos danosos. $\mathrm{Na}$ área criminal essas intervenções podem ser acompanhadas por experiências de exclusão, estigmatização e constrangimento.

Desse ponto de vista, as penas e medidas alternativas alinham-se às proposições do direito penal mínimo, que busca limitar o alcance e a intensidade da ação penal, defendido por autores, entre os quais Baratta (2014), Zaffaroni (1991) e Zaffaroni e Pierangeli (2015). Nessa perspectiva, entende-se que os substitutivos penais possibilitem a redução do dano do uso da violência do Estado, notadamente no que se refere à privação da liberdade e de outros direitos fundamentais.

As vantagens das penas e medidas alternativas em relação à prisão já foram amplamente analisadas, principalmente na produção teórica da área do Direito (BITENCOURT, 2004; GOMES, 2000; JESUS, 2000; GOMES, 2008) dentre outros. Ainda que não se disponha de estudos estatísticos que possibilitem o conhecimento das reais taxas de reincidência, acredita-se que os substitutivos penais apresentem níveis bem inferiores em relação à prisão e representem menores custos ${ }^{6}$.

Embora se reconheçam os avanços obtidos mediante a adoção das penas e medidas alternativas, é importante que se reflita sobre as tensões e contradições presentes nesse campo. Os aspectos contraditórios das penas e medidas alternativas são abordados por alguns autores, dentre os quais Azevedo (2005), Berdet (2015) e Junqueira (2018).

\footnotetext{
${ }^{5}$ Para Zaffaroni $(1988,1991)$ e Zaffaroni e Pierangeli (2015), a finalidade do direito penal é a contenção do poder punitivo. No conjunto de sua obra os direitos humanos são situados como base fundamental de suas propostas, servindo como parâmetro para o estabelecimento de limites à atuação do sistema penal como um todo.

${ }^{6}$ Embora seja menos dispendiosa se comparada à pena de prisão, a execução das penas e medidas alternativas demanda aspectos estruturais significativos, objetivando o seu acompanhamento, monitoramento e fiscalização.
} 
Um dos aspectos contraditórios dos substitutivos penais é o fato de não terem significado a diminuição da população carcerária, constituindo uma espécie de sistema "complementar" e ampliando o controle social para além dos muros da prisão. Conforme Berdet (2015, p. 74) ressalta, "se o uso das penas alternativas como controle penal extramuros está em expansão, e o encarceramento mostra-se também em crescimento, a conclusão é que houve o alargamento do sistema penal punitivo".

Outro aspecto contraditório nesse campo, salientado por Berdet (2015), é a dualidade na comunicação do seu significado social. Para o autor, diferente das penas privativas de liberdade, as penas alternativas não comunicam diretamente o seu caráter punitivo, sendo ressaltados seus propósitos de "responsabilização na comunidade", "garantia de cidadania" e "reconhecimento de direitos do infrator." (BERDET, 2015).

A falta de clareza em relação à dimensão punitiva dessas penas e medidas, por um lado restringe as possibilidades de efetiva substituição em relação à prisão, pois acabam sendo consideradas muito "brandas". Ao invés de configurarem uma "alternativa", tornam-se um "complemento", aumentando o número de pessoas submetidas ao sistema penal como um todo (BERDET, 2015). Por outro lado, a retórica que desconsidera os aspectos punitivos das penas e medidas alternativas acaba por torná-las mais "palatáveis" em relação à prisão, e ao serem anunciadas como possibilidades de promoção de direitos dos seus cumpridores, assumem, nos termos de Berdet (2015), uma "identidade esquizofrênica", porque propõem a garantia da cidadania pela via penal.

A discussão sobre o perfil dos cumpridores das penas e medidas alternativas também merece destaque na reflexão sobre as contradições presentes nesse campo. A pesquisa do ILANUD (2006) já indicava as semelhanças das características socioeconômicas dos seus destinatários em relação à população carcerária, embora fossem diferentes os delitos praticados, contribuindo para o baixo impacto na diminuição do número de presidiários.

Outras pesquisas, dentre as quais a de Junqueira (2010) e de Berdet (2015), revelam uma caracterização comum do perfil dos cumpridores de penas e medidas alternativas e da população carcerária. Em síntese, trata-se de pessoas majoritariamente pobres, com pouca escolaridade e qualificação profissional, sendo os delitos praticados, em sua maioria, contra o patrimônio. Tais características evidenciam que a seletividade do sistema criminal perpassa o 
universo das penas e medidas alternativas que, semelhante à prisão, contemplam com maior força as pessoas que vivenciam mais intensamente as expressões da questão social’

As contradições presentes nas penas e medidas alternativas conduzem ao questionamento do seu significado social, político e penológico. Ainda que representem avanços em relação à prisão, não conseguem significar processos de ruptura e superação da ordem estabelecida, reproduzindo o sistema punitivo fundado em dada estrutura social ${ }^{8}$.

É possível afirmar que as penas e medidas alternativas, mesmo que recebam o lustro justificatório da inclusão social e da garantia de direitos de cidadania, não deixam de ser uma punição criminal, atendendo aos interesses de maior demanda punitiva e controle social que marcam o tempo presente. Conforme demonstra Wacquant $(2001,2013)$, ao analisar a realidade estadunidense, os processos de reestruturação do capital desencadearam (e ainda desencadeiam) forte ataque ao Estado Social, resultando na retração dos investimentos públicos nas políticas sociais e fortalecendo o que o autor denomina Estado Penal. Nesse cenário, o aumento do controle social pela via penal não se limitou à aplicação da pena de prisão, de maneira que outras modalidades punitivas (dentre elas as penas e medidas alternativas) também tiveram significativo crescimento, contribuindo para o fortalecimento e expansão do referido Estado Penal.

A reflexão sobre as contradições presentes nas penas e medidas alternativas remetem ainda à discussão sobre o trabalho dos técnicos que atuam nesse campo, notadamente os assistentes sociais. Salienta-se que a execução dessas penas e medidas, em geral, é conduzida por esses profissionais, que lançam mão de um conjunto de instrumentos e técnicas para o alcance de determinadas finalidades.

Em um cenário marcado por avanços em relação à prisão, rupturas, contradições e desafios, os assistentes sociais se movimentam, construindo saberes e intervenções. No espaço do cotidiano, palco em que as relações sociais de reprodução e dominação se

\footnotetext{
${ }^{7}$ A questão social, conforme lamamoto (2007, p. 156), “[...] condensa o conjunto das desigualdades e lutas sociais, produzidas e reproduzidas no movimento contraditório das relações sociais, alcançando plenitude de suas expressões e matizes em tempo de capital fetiche". Sua gênese na sociedade burguesa "[...] deriva do caráter coletivo da produção contraposto à apropriação privada do trabalho, das condições necessárias à sua realização e seus frutos" (IAMAMOTO, 2007, p. 156).

${ }^{8}$ A obra Punição e Estrutura Social, de Rusche e Kirchheimer (1939), inaugura a abordagem marxista sobre a punição, relacionando-a a determinações mais amplas, notadamente de ordem econômica. Situando as penas como uma construção histórica, os autores refletem sobre a adoção de determinados métodos de punição nos diferentes períodos, afirmando que "todo sistema de produção tende a descobrir formas punitivas que correspondem às suas relações de produção” (RUSCHE; KIRCHHEIMER, 2004, p. 20).
} 
concretizam e se afirmam (PAULO NETTO; CARVALHO, 1996), esses profissionais exercem o seu trabalho, marcado por limites e possibilidades.

As penas e medidas alternativas, analisadas sob a perspectiva da categoria totalidade $^{9}$, são parte de um complexo mais amplo - o sistema penal. Os estudos baseados nas teorias da Criminologia Crítica $^{10}$ revelam que o sistema penal se caracteriza pela seletividade, estigmatização, violência e reprodução. Portanto, ainda que em menor grau em relação à prisão, os substitutivos penais carregam em si as características desse sistema do qual fazem parte, compartilhando suas finalidades de manutenção de determinada estrutura de poder e de modelo de sociedade.

Partindo-se de uma perspectiva macrossocietária, que considere o sistema penal como um todo e suas relações com as questões estruturais, é evidente que os profissionais dificilmente poderão ultrapassar os limites colocados pelo âmbito de sua intervenção. Contudo, desocultar a realidade é possível e necessário, configurando um esforço imprescindível para a descoberta das possibilidades de construção de práticas menos autoritárias, violentas e estigmatizantes no cotidiano de trabalho do assistente social.

\section{A Dimensão Técnico-Operativa do Serviço Social}

A discussão sobre a dimensão técnico-operativa assume especial importância em uma profissão interventiva no âmbito da questão social. Conforme afirma Guerra (2012, p. 40), essa dimensão constitui o "modo de aparecer da profissão", embora não se reduza a ela.

Apesar da relevância, a discussão sobre instrumentos e técnicas tem sido negligenciada na produção teórica do Serviço Social. Em pesquisa bibliográfica que contemplou a produção dos assistentes sociais referente aos anos 1990 a 2008, Santos e Noronha (2013) identificaram poucas referências que dessem destaque a essa dimensão do trabalho profissional.

Em um contexto fortemente marcado pelo avanço do conservadorismo e por transformações na formação profissional que apontam para processos de precarização é

\footnotetext{
${ }^{9} \mathrm{~A}$ categoria totalidade, que permite uma leitura ampla e complexa do real, pode ser compreendida na expressão "tudo se relaciona" (GADOTTI, 1983, p. 24). Para a dialética marxista, os objetos e fenômenos são ligados entre si, de maneira que se condicionam reciprocamente.

${ }^{10}$ Rompendo com as origens da Criminologia, ligadas a uma concepção tradicional que se debruçava sobre o enfoque etiológico do crime, ou seja, sobre suas causas individuais e motivações, a Criminologia Crítica surgiu a partir dos anos 1960, nos Estados Unidos e na Europa, e promoveu uma profunda crítica do direito penal moderno e suas instituições.
} 
fundamental a abordagem dos instrumentos e técnicas a partir de um olhar crítico. Tal perspectiva contribui para superar concepções que deixam de articular a dimensão técnicooperativa aos fundamentos ético-políticos e teórico-metodológicos do Serviço Social, desconsiderando as mediações necessárias para a compreensão e a intervenção na realidade.

A escolha dos instrumentos e técnicas relaciona-se diretamente aos objetivos e às finalidades da profissão. São meios, portanto, de atingir esses objetivos e finalidades, não possuindo um fim em si mesmo. É nessa perspectiva que Guerra $(2014$, p. 34) define os instrumentos de trabalho do assistente social:

[...] elementos postos na relação entre o assistente social e os usuários, na perspectiva de efetivar respostas planejadas e projetadas pelo profissional. Serão acionados, mobilizados, utilizados, criados em consonância com as finalidades da intervenção profissional, contribuindo para a passagem da teoria à prática, do ideal ao real. São eles que permitem materializar os objetivos profissionais através de ações concretas.

É importante salientar ainda que, para a referida autora, a questão dos instrumentos - como fazer - deve estar associada a outras dimensões do trabalho profissional - o que, por que, para que, quando, onde e com que meios fazer. Dessa maneira supera-se uma visão limitada e formalista do trabalho do assistente social em direção à perspectiva da instrumentalidade, ou seja, da busca pelos fundamentos teóricos, éticos e políticos nos quais se assentam a profissão (GUERRA, 2014).

Munidos de valores, princípios, conhecimentos, técnicas e habilidades, os assistentes sociais materializam suas ações nas penas e medidas alternativas, movimentando-se entre as condições objetivas colocadas à intervenção profissional pelos espaços de trabalho nos quais estão inseridos. Tais espaços definem limites e possibilidades para a efetivação das respostas planejadas e projetadas pelos profissionais.

Diante dos limites e das possibilidades colocadas aos assistentes sociais é fundamental a capacidade de analisar criticamente a realidade, principalmente suas contradições. A complexidade do real exige competência teórica e metodológica para a compreensão das funções ideológicas do discurso penal, possibilitando a construção de uma leitura isenta de "ilusões", ou seja, de um posicionamento e de uma ação consciente pela profissão.

O Serviço Social brasileiro é norteado por um projeto ético-político profissional hegemônico. De acordo com esse projeto, os assistentes sociais assumem o compromisso com 
a defesa intransigente dos direitos humanos, com a ampliação da cidadania, com a qualidade dos serviços prestados e com a luta em favor da equidade e da justiça social.

O projeto ético-político profissional do Serviço Social materializa-se (ou não) nas intervenções cotidianas dos profissionais. Diante dos valores e princípios assumidos pela profissão, é importante que se privilegie a utilização de instrumentos que favoreçam a democratização das informações no espaço institucional, aspecto indispensável à participação dos usuários. Tal perspectiva assume especial dimensão quando se trata do campo sociojurídico, composto por instituições que têm o exercício do controle social como uma de suas ações prioritárias ${ }^{11}$.

\section{Dimensão Técnico-Operativa do Trabalho do Assistente Social na Execução das Penas e Medidas Alternativas: Apresentação dos Resultados da Pesquisa Documental e Bibliográfica}

No processo histórico em que ocorre a gênese e a legitimação do Serviço Social, no caso brasileiro, a partir dos anos 1930, as instituições que compõem o campo sociojurídico se colocam entre as pioneiras no acolhimento da profissão. Conforme lamamoto e Carvalho (1996), no Rio de Janeiro o Juizado de Menores e o Serviço de Assistência ao Menor da Prefeitura foram as primeiras instituições públicas a contratá-los. Já Fávero $(1999,2003)$ e Fávero, Melão e Jorge (2005) se referem que a inserção da profissão no Poder Judiciário paulista teve início ainda na década de 1940, no Juizado de Menores.

Ainda que a inserção dos assistentes sociais no campo sociojurídico possa ser considerada "tradicional", pois, há um significativo período de tempo essas instituições contam com assistentes sociais em seus quadros, a execução das penas e medidas alternativas constitui um espaço sócio-ocupacional relativamente recente para o Serviço Social. É a partir da década de 1980 que se inaugura, no Brasil, a possibilidade de aplicação dessas penas e medidas a delitos considerados de menor gravidade. Diante dessa previsão legal, é criada a demanda de profissionais que atuem nessa área, dentre eles o assistente social.

\footnotetext{
${ }^{11}$ De acordo com o documento "Atuação de Assistentes Sociais no Sociojurídico: subsídios para reflexão", elaborado pelo Conselho Federal de Serviço Social (CFESS) no ano de 2014, o Serviço Social no campo sociojurídico compreende o Poder Judiciário, a Defensoria Pública, o Ministério Público, os sistemas prisional e de segurança, as organizações que executam medidas socioeducativas com adolescentes, dentre outros (CFESS, 2014).
} 
É importante salientar que a legislação brasileira que trata sobre as penas e medidas alternativas não se refere à participação dos técnicos, nem mesmo a Lei de Execução Penal (LEP) de 1984, que dedica 1 seção (VI), 2 artigos e 7 incisos, ao trabalho do profissional de Serviço Social na execução da pena privativa de liberdade. Nesse sentido, as Regras de Tóquio, de 1990, configuram uma das principais referências para o trabalho dos técnicos nesse campo, pois dedica uma seção (VI) para tratar desse assunto ${ }^{12}$.

Somente no ano de 2002 foi publicado um documento de abrangência nacional (ainda que sem força de lei) que define uma metodologia de apoio técnico para a execução das penas e medidas alternativas. O Manual de Monitoramento das Penas e Medidas Alternativas, publicado pelo Ministério da Justiça, constitui o principal documento analisado na pesquisa que ora se apresenta, dada a sua representatividade, pois foi elaborado "com base na experiência técnica de vários estados do país" (BRASIL, 2002, p. 2), relevância e ineditismo.

O referido Manual pressupõe a execução dessas penas e medidas ${ }^{13}$ por profissionais da área "psicossocial" inseridos nas Varas de Execução de Penas Alternativas, vinculadas ao Poder Judiciário, e nas Centrais de Apoio às Penas e Medidas Alternativas, vinculadas ao Poder Executivo $^{14}$. A Resolução no 6, de 25 de novembro de 2009, pelo Conselho Nacional de Política Criminal e Penitenciária (CNPCP), e a Resolução no 101, de 15 de dezembro de 2009, pelo Conselho Nacional de Justiça (CNJ), corroboram e recomendam esse modelo para o fomento e a execução das penas e medidas alternativas no Brasil (BRASIL, 2009a , 2009b).

No Manual de Monitoramento das Penas e Medidas Alternativas a função dos técnicos é definida como acompanhamento das penas e medidas, sendo explicitado que a fiscalização é de "natureza jurídico-legal como resposta a um ato delituoso" (BRASIL, 2002, p.

\footnotetext{
${ }^{12}$ A seção VI, referente ao tema "Pessoal”, nas observações gerais, diz o seguinte: “O caráter exigente e complexo da execução de medidas não-privativas de liberdade faz com que seja fundamental que os funcionários possuam conhecimentos profissionais, habilidades e experiência. Por conseguinte, é preciso recrutá-los, selecioná-los, treiná-los e dar-lhes apoio de forma que se garanta sua necessária competência profissional" (JESUS, 2000, p. 262).

${ }^{13} \mathrm{O}$ documento refere que os instrumentos de trabalho apresentados dizem respeito à execução da prestação de serviço à comunidade, prestação pecuniária, limitação de fim de semana e medida de tratamento.

${ }^{14}$ O Manual de Gestão para Alternativas Penais: penas restritivas de direitos, de 2016, define a composição da equipe técnica da seguinte maneira: “o corpo técnico das Centrais é formado por equipe multidisciplinar com atuação interdisciplinar, composta por profissionais das áreas das ciências sociais e humanas, tendo em seu quadro, preferencialmente, profissionais da psicologia, do serviço social e do direito. [...] Esta estrutura mínima é condição para se garantir a efetividade de uma metodologia interinstitucional e interdisciplinar, além de garantir a participação social" (BRASIL, 2016b, p. 33).
} 
13), dizendo respeito, portanto, ao "mundo jurídico" (BRASIL, 2002, p. 17). Preconiza-se a metodologia de apoio técnico com base em três módulos:

\footnotetext{
- avaliação, corresponde ao procedimento técnico que faz a análise do perfil do beneficiário e da entidade parceira.

- encaminhamento, corresponde ao procedimento técnico que assegura a relação formal entre o juízo da execução, o beneficiário e a entidade parceira.

- acompanhamento, corresponde ao procedimento técnico que garante a fiscalização do fiel cumprimento da pena ou medida alternativa (BRASIL, 2002, p. 10).
}

Vale ressaltar que, ao anunciar os módulos básicos do trabalho desenvolvido pelos técnicos, o conteúdo do referido Manual evidencia a dificuldade de separação entre as dimensões de acompanhamento e fiscalização das penas e medidas alternativas. Ainda que se afirme que o trabalho desenvolvido pelos profissionais diga respeito somente à primeira dimensão, ambas não estão descoladas, mas em permanente relação (dialética).

O Manual de Monitoramento das Penas e Medidas Alternativas prevê ainda um "módulo complementar", voltado à captação, cadastramento e capacitação de entidades parceiras. Tais entidades, devidamente conveniadas com o Poder Judiciário, formam o que o documento denomina rede social de apoio, ou seja, instituições (públicas ou sem fins lucrativos) que recebem pessoas para cumprimento de prestação de serviços à comunidade e também recursos financeiros decorrentes das penas pecuniárias mediante a apresentação de projetos à Vara de Execução Criminal ${ }^{15}$.

O citado Manual preconiza, fundamentalmente, o atendimento aos cumpridores de penas ou medidas alternativas (avaliação, encaminhamento e acompanhamento) e às instituições conveniadas (captação, cadastramento e capacitação). O documento recomenda ainda uma série de documentos para registro e comunicação das atividades profissionais (fichas de encaminhamentos, relatórios de atendimentos, modelos de avaliação etc.).

Na pesquisa bibliográfica realizada para este estudo foram analisadas 46 bibliografias produzidas pelo Serviço Social entre os anos 2000 a 2016 sobre o trabalho do assistente social nas penas e medidas alternativas ${ }^{16}$. Em 25 estudos são explicitados os instrumentos utilizados pelos profissionais, conforme o quadro 1 , a seguir:

\footnotetext{
${ }^{15}$ No ano de 2012 o Conselho Nacional de Justiça (CNJ) expediu a Resolução no 154 que estabeleceu a política institucional do Poder Judiciário referente a verbas provenientes de prestação pecuniária, depositadas em conta única e geridas pela Vara de Execução Criminal (BRASIL, 2012).

${ }^{16} \mathrm{O}$ corpus da pesquisa foi composto pelas seguintes fontes: 4 dissertações de mestrado, 15 trabalhos de conclusão de cursos de graduação, 4 artigos publicados em revistas da área e 23 artigos publicados em anais dos principais eventos da área (Encontro Nacional de Pesquisadores em Serviço Social e Congresso Brasileiro
} 
Quadro 1: Estudos que explicitam os instrumentos utilizados

\begin{tabular}{|c|c|c|}
\hline Tipo de estudo & Total de Estudos & Estudos que explicitam os instrumentos \\
\hline Dissertações de Mestrado & 04 & 02 \\
\hline TCCs & 15 & 11 \\
\hline Artigos em Anais & 23 & 10 \\
\hline Artigos em Revista & 04 & 02 \\
\hline Total & 46 & 25 \\
\hline
\end{tabular}

Fonte: A autora (2018).

A análise bibliográfica revelou que a maior parte dos trabalhos era resultante de experiências de estágio, ou seja, da inserção dos alunos nos diferentes espaços sócioocupacionais. Além dos 15 trabalhos de conclusão de curso, 7 publicações analisadas partiam do processo de formação profissional, totalizando 22 estudos. Pode-se afirmar, com base nesses dados, que a formação profissional constitui o lócus privilegiado da produção bibliográfica da área sobre penas e medidas alternativas no país.

Embora nem todas as bibliografias oriundas de práticas de estágio configurem relatos de experiência, pois algumas delas apresentam resultados de pesquisa, todas possuem vinculação direta com a dimensão técnico-operativa, ou seja, com a denominada intervenção profissional. Tal característica, por um lado, revela a possibilidade de articulação da discussão das penas e medidas alternativas com a realidade mediante a sistematização do conhecimento produzido pela profissão, trazendo para o centro do debate o trabalho cotidiano do assistente social. Por outro lado, a pouca produção da área na pós-graduação revela restrito movimento da categoria profissional no sentido de aprofundar teoricamente o tema. Nessa perspectiva, é possível afirmar a necessidade de aprofundamento teórico sobre o assunto, demandando a realização de pesquisas que contribuam para a construção crítica de conhecimentos.

As informações coletadas revelaram que os instrumentos utilizados pelos assistentes sociais na execução das penas e medidas alternativas alinham-se ao que é preconizado pelo Manual de Monitoramento das Penas e Medidas Alternativas, conforme o quadro 2, a seguir.

Quadro 2 - Principais instrumentos utilizados pelos assistentes sociais

\begin{tabular}{|l|c|}
\hline \multicolumn{1}{|c|}{ Instrumento } & $\begin{array}{c}\text { Número de trabalhos que referem o uso } \\
\text { do instrumento }\end{array}$ \\
\hline Entrevista com cumpridores & 25 \\
\hline Visita institucional & 13 \\
\hline
\end{tabular}

de Serviço Social). É importante salientar que não foi identificada tese de doutorado no período analisado que tratasse especificamente sobre o trabalho do assistente social nas penas e medidas alternativas. 


\begin{tabular}{|l|l|}
\hline $\begin{array}{l}\text { Encontros, reuniões ou capacitações das instituições } \\
\text { conveniadas }\end{array}$ & 10 \\
\hline Contatos institucionais & 09 \\
\hline Visita domiciliar & 09 \\
\hline Grupos ou palestras com cumpridores & 05 \\
\hline Produção de informativos, manuais ou boletins informativos & 04 \\
\hline
\end{tabular}

Fonte: A autora (2018).

As informações coletadas mostram a entrevista como instrumento mais empregado pelos assistentes sociais na execução dos substitutivos penais. Trata-se de um instrumento tradicional da profissão, utilizado desde os seus primórdios (LEWGOY; SILVEIRA, 2007).

A larga utilização da entrevista, somada à menor citação de abordagens grupais, denota que a profissão privilegia a abordagem individual no atendimento aos cumpridores de penas e medidas alternativas. Ainda que tal abordagem seja válida e necessária, é importante que se reflita sobre suas implicações em instituições que têm como prerrogativas o disciplinamento de conflitos e o controle social, tendendo, portanto, a moralizar e a individualizar expressões da questão social.

De acordo com Santos (2013), o processo de escolha dos instrumentos não é neutro, sendo sempre orientado por valores, princípios e por determinada teoria social, ainda que o profissional não tenha plena consciência disso. Há, portanto, sempre uma intencionalidade guiando a prática, de maneira que a dimensão técnico-operativa coloca em movimento as demais dimensões do trabalho profissional (teórico-metodológica e ético-política).

As abordagens coletivas assumem especial relevância no âmbito da execução das penas e medidas alternativas, especialmente por serem mais propícias à busca pela universalização das questões apresentadas pelas instituições como de caráter individual. Vale salientar que as abordagens de grupo favorecem a troca de experiências, a participação e a organização coletivas dos usuários.

Ressalta-se ainda a utilização, embora em pequena escala, de materiais informativos na execução das penas e medidas alternativas. Tais materiais constituem um importante instrumento para a democratização das informações, notadamente no que diz respeito aos direitos e deveres dos cumpridores e demais envolvidos na execução dos substitutivos penais. Recomenda-se, portanto, maior investimento dos profissionais nesses materiais informativos, dadas as suas possibilidades de contribuir para a construção de intervenções menos autoritárias e estigmatizantes, reduzindo o dano inerente ao aparato punitivo do Estado. 


\section{Considerações Finais}

No presente artigo foram tecidas algumas considerações sobre a dimensão técnicooperativa do trabalho do Assistente Social na execução das penas e medidas alternativas a partir de uma pesquisa documental e bibliográfica. Acredita-se que a profissão tenha muito a contribuir no que diz respeito à reflexão sobre os limites e as possibilidades do trabalho desenvolvido nessa área. Para tanto, é fundamental que se invista na sistematização do trabalho cotidiano e no fortalecimento da dimensão investigativa do Serviço Social, estabelecendo-se as relações necessárias entre as expressões concretas da questão social com a totalidade e suas múltiplas e articuladas determinações.

A dimensão técnico-operativa não pode ser considerada isoladamente, pois carrega em si as demais dimensões do trabalho do assistente social (ético-política e teóricometodológica). Analisado sob a perspectiva da categoria totalidade, o trabalho do assistente social nas penas e medidas alternativas é parte de um complexo mais amplo - o sistema penal, trazendo suas características e, principalmente, suas contradições. Ao movimentar seus instrumentais de trabalho, o profissional deverá levar em conta esses aspectos, analisando criticamente sua participação no exercício do controle social por parte do Estado e desvelando as possibilidades de construção de intervenções que possam mitigar os efeitos danosos na vida dos usuários.

É nesse contexto que os assistentes sociais que trabalham na execução dos substitutivos penais se movimentam cotidianamente. Em meio a possibilidades, limites e desafios, em um terreno complexo e contraditório, os profissionais devem buscar o fortalecimento de práticas de resistência, contribuindo para a construção de intervenções menos autoritárias e estigmatizantes.

\section{Referências}

AZEVEDO, Mônica Louise de. Penas alternativas à prisão: os substitutivos penais no sistema penal brasileiro. Curitiba: Juruá, 2005.

BARATTA, Alessandro. Criminologia crítica e crítica do direito penal: introdução à sociologia do direito penal. 6. ed. Rio de Janeiro: Revan, 2014.

BARRETO, Fabiana Costa Oliveira. Dez anos da política nacional de penas e medidas alternativas. Brasília: Ministério da Justiça, 2010. 
BATISTA, Vera Malaguti. Introdução crítica à criminologia brasileira. 2. ed. Rio de Janeiro: Revan, 2015.

BERDET, Marcelo Borba. Os significados da punição nas penas alternativas. 2015. Tese (Doutorado em Sociologia) - Universidade de Brasília, Brasília, 2015.

BITENCOURT, Cezar Roberto. Falência da pena de prisão: causas e alternativas. São Paulo: Saraiva, 2004.

BRASIL. Conselho Nacional de Justiça. Resolução no 101, de 15 de dezembro de 2009. Define a política institucional do Poder Judiciário na Execução das Penas e Medidas Alternativas à Prisão. Brasília: CNJ, 2009a. Disponível em:

https://atos.cnj.jus.br/files/resolucao_101_15122009_11102012190042.pdf. Acesso em: 15 jul. 2013.

BRASIL. Conselho Nacional de Justiça. Resolução no 154, de 13 de julho de 2012. Define a política institucional do Poder Judiciário na utilização dos recursos oriundos da aplicação da pena de prestação pecuniária. Brasília: CNJ, 2012. Disponível em:

https://atos.cnj.jus.br/files/resolucao_154_13072012_21012019172816.pdf. Acesso em: 15 jul. 2013.

BRASIL. Conselho Nacional de Política Criminal e Penitenciária. Resolução $n$ o 6, de 25 de novembro de 2009. Brasília: CNPCP, 2009b. Disponível em:

http://depen.gov.br/DEPEN/depen/cnpcp/resolucoes/2009/resolucaono06de25denovembr ode2009.pdf. Acesso em: 15 jul. 2013.

BRASIL. Decreto no 592, de 6 de julho de 1992. Atos Internacionais. Pacto Internacional sobre Direitos Civis e Políticos. Promulgação. Brasília: Presidência da República, 1992. Disponível em: http://www.planalto.gov.br/ccivil_03/decreto/1990-1994/D0592.htm. Acesso em: 1. fev. 2009.

BRASIL. Ministério da Justiça. Postulados, princípios e diretrizes para a política nacional de alternativas penais. Brasília: MJ, $2016 \mathrm{a}$.

BRASIL. Ministério da Justiça. Secretaria Nacional de Justiça. Central Nacional de Apoio e Acompanhamento às Penas e Medidas Alternativas. Manual de monitoramento das penas e medidas alternativas. Brasília: MJ, 2002.

BRASIL. Ministério da Justiça. Secretaria Nacional de Justiça. Departamento Penitenciário Nacional. Manual de gestão para alternativas penais: penas restritivas de direitos: procedimentos, fluxos e rotinas para aplicação e acompanhamento. Brasília: MJ, 2016b.

CFESS - CONSELHO FEDERAL DE SERVIÇO SOCIAL. Atuação de assistentes sociais no sociojurídico: subsídios para reflexão. Brasília: CFESS, 2014. Disponível em: http://www.cfess.org.br/arquivos/CFESSsubsidios_sociojuridico2014.pdf. Acesso em: 20 jun. 2018.

FÁVERO, Eunice Teresinha. O estudo social: fundamentos e particularidades de sua construção na área judiciária. In: CFESS - CONSELHO FEDERAL DE SERVIÇO SOCIAL (org.). $O$ estudo social em perícias, laudos e pareceres técnicos. São Paulo: Cortez, 2003. p. 9-51. 
FÁVERO, Eunice Teresinha. Serviço social, práticas judiciárias, poder: implantação e implementação do serviço social no juizado de menores de São Paulo. São Paulo: Veras Editora, 1999.

FÁVERO, Eunice Teresinha; MELÃO, Magda Jorge Ribeiro; JORGE, Maria Rachel Tolosa (org.). O serviço social e a psicologia no poder judiciário: construindo saberes, conquistando direitos. São Paulo: Cortez, 2005.

GADOTTI, Moacir. Concepção dialética da educação: um estudo introdutório. 2. ed. São Paulo: Cortez, 1983.

GOMES, Geder Luiz Rocha. A substituição da prisão, alternativas penais: legitimidade e adequação. Salvador: Podium, 2008.

GOMES, Luiz Flávio. Penas e medidas alternativas à prisão. 2. ed. São Paulo: Revista dos Tribunais, 2000.

GUERRA, Yolanda. A dimensão técnico-operativa do exercício profissional. In: SANTOS, Cláudia Mônica dos; BACKX, Sheila; GUERRA, Yolanda (org.). A dimensão técnico-operativa no serviço social: desafios contemporâneos. Juiz de Fora: Editora UFJF, 2012.

GUERRA, Yolanda. A instrumentalidade do serviço social. 10. ed. São Paulo: Cortez, 2014.

IAMAMOTO, Marilda Villela. Serviço social em tempo de capital fetiche: capital financeiro, trabalho e questão social. São Paulo: Cortez, 2007.

IAMAMOTO, Marilda Villela; CARVALHO, Raul de. Relações sociais e serviço social no Brasil: esboço de uma interpretação histórico-metodológica. 11. ed. São Paulo: Cortez, 1996.

ILANUD - INSTITUTO LATINO AMERICANO DAS NAÇÕES UNIDAS PARA A PREVENÇÃO DO DELITO E TRATAMENTO DO DELINQUENTE. Levantamento nacional sobre a execução de penas alternativas: relatório final de pesquisa. São Paulo: ILANUD, 2006.

JESUS, Damásio Evangelista de. Penas alternativas: anotações à Lei no 9.714, de 25 de novembro de 1998. São Paulo: Saraiva, 2000.

JUNQUEIRA, Maíz Ramos. Penas e medidas alternativas e serviço social: entre a garantia de direitos e o controle social. 2018. Tese (Doutorado em Serviço Social) - Pontifícia Universidade Católica do Rio Grande do Sul, Porto Alegre, 2018.

JUNQUEIRA, Maíz Ramos. Prestação de serviços à comunidade: impacto e (in)visibilidade no cumprimento da pena/medida alternativa. 2010. Dissertação (Mestrado em Educação) Universidade Federal do Rio Grande do Sul, Porto Alegre, 2010.

LEWGOY, Alzira Maria Baptista; SILVEIRA, Esalba Maria Carvalho. A entrevista nos processos de trabalho do assistente social. Textos e Contextos, Porto Alegre, v. 6, n. 2, p. 233-251, 2007.

MORAES, Roque; GALIAZZI, Maria do Carmo. Análise textual discursiva. 2. ed. Ijuí: Editora UNIJUÍ, 2011. 
ONU - ORGANIZAÇÃO DAS NAÇÕES UNIDAS. Declaração universal dos direitos humanos. Paris: ONU, 1948. Disponível em:

https://www.ohchr.org/EN/UDHR/Documents/UDHR_Translations/por.pdf. Acesso em: 1 fev. 2009.

ONU - ORGANIZAÇÃO DAS NAÇÕES UNIDAS. Regras mínimas para o tratamento dos reclusos. Genebra: ONU, 1955. Disponível em:

http://www.direitoshumanos.usp.br/index.php/Direitos-Humanos-na-

Administra\%C3\%A7\%C3\%A3o-da-Justi\%C3\%A7a.-Prote\%C3\%A7\%C3\%A3o-dos-Prisioneirose-Detidos.-Prote\%C3\%A7\%C3\%A3o-contra-a-Tortura-Maus-tratos-e-

Desaparecimento/regras-minimas-para-o-tratamento-dos-reclusos.html. Acesso em: 1 fev. 2009.

PAULO NETTO, José; CARVALHO, Maria do Carmo Brant de. Cotidiano: conhecimento e crítica. 4. ed. São Paulo: Cortez, 1996.

PIMENTA, Victor Martins. Fundamentos para a política penal alternativa. ARACÊ: Direitos Humanos em Revista, [S. I.], v. 4, n. 5, p. 14-34, 2017.

RUSCHE, Georg; KIRCHHEIMER, Otto. Punição e estrutura social. 2. ed. Rio de Janeiro: Revan, 2004.

SANTOS, Cláudia Mônica dos. Na prática a teoria é outra? Mitos e dilemas na relação entre teoria, prática, instrumentos e técnicas no serviço social. 3. ed. Rio de Janeiro: Lumen Juris, 2013.

SANTOS, Cláudia Mônica dos; NORONHA, Karine. O estado da arte sobre os instrumentos e técnicas na intervenção profissional do assistente social: uma perspectiva crítica. In: FORTI, Valéria; GUERRA, Yolanda (org.). Serviço social: temas, textos e contextos. 4. ed. Rio de Janeiro: Lumen Juris, 2013. p. 47-63.

WACQUANT, Loïc. As prisões da miséria. Rio de Janeiro: Jorge Zahar Editor, 2001.

WACQUANT, Loïc. Punir os pobres: a nova gestão da miséria nos Estados Unidos. 3. ed. Rio de Janeiro: Revan, 2013.

ZAFFARONI, Eugenio Raúl. Criminología: aproximación desde un margen. Bogotá: Editorial Temis, 1988. v. 1.

ZAFFARONI, Eugenio Raúl. La filosofía del sistema penitenciario en el mundo contemporáneo. In: BELOFF, Mary Ana; BOVINO, Alberto; COURTIS, Christian (org.). Cuadernos de la cárcel. Buenos Aires: No Hay Derecho, 1991. p. 36-62.

ZAFFARONI, Eugenio Raúl; PIERANGELI, José Henrique. Manual de direito penal brasileiro: parte geral. 11. ed. São Paulo: Revista dos Tribunais, 2015.

Recebido em: 07.02.2019

Aceito em: 15.04.2020 